\title{
Oxygen and ionic transport in hydrogel and silicone-hydrogel contact lens materials: An experimental and theoretical study
}

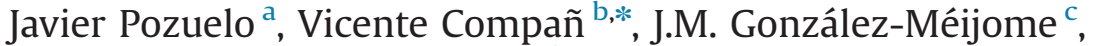 \\ María González ${ }^{\mathrm{a}}$, Sergio Mollá ${ }^{\mathrm{b}}$ \\ a Departamento de Ciencia e Ingeniería de Materiales e Ingeniería Química (IAAB), Universidad Carlos III de Madrid, 28911 Leganés, Madrid, Spain \\ ${ }^{\mathrm{b}}$ Departamento de Termodinámica Aplicada, Universidad Politécnica de Valencia, C/Camino de Vera s/n, 46020 Valencia, Spain \\ ${ }^{\mathrm{c}}$ Clinical and Experimental Optometry Research Lab, Center of Physics (Optometry), University of Minho, Braga, Portugal
}

\section{A R T I C L E I N F O}

\section{Article history:}

Received 19 July 2013

Received in revised form

1 October 2013

Accepted 6 October 2013

Available online 18 October 2013

Keywords:

Hydrogels

Silicone-Hydrogel

Molecular Dynamics Simulation

Gas transport simulation

Ionic transport simulation

\begin{abstract}
A B S T R A C T
The transport of oxygen, water and naked ions of $\mathrm{Na}^{+}$and $\mathrm{Cl}^{-}$across two kind of hydrogels materials, made of a conventional hydrogel (Hy) based on hydroxyethyl methacrylate (pHEMA) and a silicone hydrogel ( $\mathrm{Si}-\mathrm{Hy})$ material containing siloxane moieties, was compared between Molecular Dynamics Simulations (MDS) and experimental measurements. Computer-assisted simulations were carried out for wet hydrogels at $310 \mathrm{~K}$ and equilibrium water uptake in the range from $10 \%$ to $40 \%$. Our results show that in Si-Hy materials the aqueous hydrogel and hydrophobic siloxane phases are separated suggesting a co-continuous structure, and oxygen moves predominantly through the free volume of the hydrophobic siloxane phase. The values of diffusion coefficient of $\mathrm{O}_{2}$, water and $\mathrm{Na}^{+}$and $\mathrm{Cl}^{-}$ions in $\mathrm{Si}-\mathrm{Hy}$ was about one order of magnitude higher than in conventional hydrogels when the water content was above $25 \mathrm{wt}$ $\%$ up to a critical value of $35 \mathrm{wt} \%$ where a percolation phenomenon is observed. The value of the oxygen diffusion coefficient obtained by simulations are roughly similar to that experimentally found using potentiostatic techniques. Values found experimentally for $\mathrm{Na}^{+}$diffusion coefficients are between three or five times lower than MDS. For Si-Hy materials with $36 \mathrm{wt} \%$ of water the $\mathrm{Na}+$ permeability, diffusion coefficient and salt partition coefficient $\left(k_{m}=P / D\right)$ are $6.7 \pm 0.2 \times 10^{-7} \mathrm{~cm}^{2} / \mathrm{s}, 1.8 \pm 0.5 \times 10^{-6} \mathrm{~cm}^{2} / \mathrm{s}$ and $0.42 \pm 0.13$, respectively. For Hy materials of $38.6 \mathrm{wt} \%$ the values found were $18.4 \pm 1.2 \times 10^{-7} \mathrm{~cm}^{2} / \mathrm{s}$, $5.4 \pm 1.0 \times 10^{-6} \mathrm{~cm}^{2} / \mathrm{s}$ and $0.34 \pm 0.09$, respectively. The coordination number between the fixed groups (-SiO-) and water in HEMA and the particles $\left(\mathrm{O}_{2}, \mathrm{Cl}^{-}\right.$and $\left.\mathrm{Na}^{+}\right)$is slightly larger than unity. The present study might be applied in the modeling of the gas transport in hydrogels as well as in novel polymeric structures for novel polymeric structures for new biomedical and technological applications with the aim of predicting and tuning their physiological behavior.
\end{abstract}

(c) 2013 Elsevier B.V. All rights reserved.

\section{Introduction}

The gas permeability in polymer films and membranes are critical aspects in food packaging, protective coating, membrane separation processes and biomedical materials. With this purpose, hydrophilic polymers prepared from very different monomers have been widely investigated in the last 30 years given the vast field of their applications in contact lenses (CL), dental materials, optical lenses, materials for encapsulated cells, carriers for controlled drug delivery, or super absorbent hydrogels to be used in different domains of the technological, agricultural, or health industry [1-7]. Many different chemical structures constitute the base of these compounds, although the main component has a

\footnotetext{
* Corresponding author. Tel.: + 34 963879328; fax: + 34963877329.

E-mail address: vicommo@ter.upv.es (V. Compañ).
}

hydrophilic character [8,9]. Particularly, hydrosoluble methacrylic monomers are employed very often to prepare wet hydrogels to be used as soft CL which represents over $90 \%$ of the global market of all lenses prescribed $[10,11]$. This kind of materials starting with the development of poly(hydroxyethyl metacrylate) (pHEMA) [10], and was followed by a variety of copolymers of HEMA and/or other hydrophilic or hydrophobic monomers, resulting in a diversity of ionic and non-ionic hydrogels lenses with different water content $[12,13]$. The knowledge of the oxygen permeability, $P=D S$, where $D$ and $S$ are respectively the diffusion coefficient and solubility through $\mathrm{CL}$, is one of the most important properties governing physiological response of the ocular surface during CL wear.

Silicones are polymers with a backbone consisting entirely of silicon-oxygen bonds (siloxane), responsible for their high gas permeability [14]. Siloxane is now present in the most recent generation of CL known as silicone hydrogels ( $\mathrm{Si}-\mathrm{Hy}$ ), combining the softness and comfort of the p-HEMA based hydrogels with 
the higher oxygen permeability typical of siloxane containing materials. Some of these materials fulfill the requirements established to be worn under open and closed eye conditions [15] and have been a breakthrough in the contact lens industry representing now, over $70 \%$ of all lenses marketed in several countries worldwide $[10,11]$.

There are few reports in the literature providing information on Molecular Dynamics Simulations (MDS) to obtain gas diffusion coefficient in wet hydrogels, but particularly the information regarding the calculation of gas solubility in these systems is scarce. This is due to the fact that the chemical potential, which plays the main role in the calculation of the solubility, is difficult to obtain in MDS. Eslami and Müller-Plathe $[16,17]$ made an exhaustive review of methods used to determine the solubility coefficient for molecular simulations. In glassy polymeric systems such as the membranes used for gas separation, in which the atomic motion is very restricted, the diffusion coefficients and solubility have been calculated by Gusev et al. [18] using the transition state approximation (TSA) method. Other authors computed the diffusion coefficient by the TSA method and gas solubility coefficient using modified Widom methods [19-25]. Monte Carlo methods and specially TSA have been widely used for determination of solubility and diffusion coefficients in rigid systems. All are based in the assumption that the only movements produced inside the host matrices are small atomic vibrations usually defined by a "smearing factor". In a system where atomic mobility is high, e.g. in a hydrogel, the use of methods such as TSA would not be applicable as this smearing factor makes no sense. In rigid membranes, gas transport happens by mean of jumps between minimum energy positions and it is not depending on structural relaxation of polymer matrices but just depends on elastic movements of the matrix; this is only true for rigid membranes. In systems where atomic mobility is less restricted or present high gas diffusion such is the case of conventional Hy and $\mathrm{Si}-\mathrm{Hy}$, the MDS is a very good method to determine the diffusion coefficient [26,27] but the determination of solubility coefficient in these systems is not fully developed. In most of these methods, the chemical potential is calculated at the end of the molecular dynamic run what complicates determination of equilibrium properties. We propose the implementation of molecular dynamic trajectory of modified particle insertion method for the study of wet hydrogels. To evaluate the method we have chosen two kinds of hydrogels based on pHEMA and Si-Hy materials commonly used in the production of soft CL with different amounts of water absorbed.

Although not as well known as oxygen permeability, hydraulic and ionic permeabilities are very important to warrant an adequate relationship between the $\mathrm{CL}$ and the ocular surface. According to Domscheke et al. [28], ion permeability of contact lenses is a critical parameter for lens movement on the eye required for post-lens tear turnover and metabolic waste removal. Thus, both, oxygen and ion transport through Hy and Si-Hy CL materials are critical properties.

In this work, the trajectories of naked $\mathrm{Na}^{+}$cations, $\mathrm{Cl}^{-}$anions, $\mathrm{H}_{2} \mathrm{O}$ and $\mathrm{O}_{2}$ molecules are simulated using full MDS at $35^{\circ} \mathrm{C}$. The simulations were carried out for pHEMA-based conventional hydrogels and $\mathrm{Si}-\mathrm{Hy}$ materials of similar composition to commercial CL with different water content proportions. Once the trajectories reach Einstein behavior, the diffusion coefficients are determined and a modified particle insertion method was used to determine the solubility coefficient of oxygen. The transport mechanism was explained for these systems. To proof the validity of our MDS we also measured experimentally the oxygen permeability, diffusion and solubility coefficients of different Hy and Si-Hy materials used in commercial CL. Similarly, diffusion and ion permeability have been obtained in Hy and Si-Hy CL materials. These kind of studies can have an important role for the design and prediction of $\mathrm{CL}$ material performance regarding the ionic diffusion and oxygen diffusion, permeability and transmissibility, as well as gas transports studies in other wet hydrogels.

\section{Materials and methods}

To evaluate the oxygen and ionic transport in Hy and Si-Hy materials we have conducted MDS and performed experimental measurements. The following sections address the methodological approaches followed. To compare the simulation results with experimental results, the values of apparent oxygen permeability, diffusion coefficient, solubility and salt permeation have been measured in eight commercial contact lenses CL of the same class of those modeled compositions. Table 1 shows the main characteristics of commercial CL used in this study: commercial name, USAN material name and water content at saturation harmonic thickness for eight different materials of Hy and Si-Hy CL. Four of them are Hy CL: Seequence (Polymacon), Proclear (Omafilcon A), Acuvue (Etafilcon A) and Newvues (Vifilcon A) manufactured by Baush\&Lomb, CooperVision, Johnson\&Johnson and Alcon (previously Ciba Vision), respectively. The other four are Si-Hy CL: Pure Vision ${ }^{\circledR}$ (Balafilcon A), Biofinity (Confilcon A), Acuvue Oasys (Senofilcon A) and Avaira (Enfilcon A) manufactured by Alcon, CooperVision, Johnson\&Johnson and CooperVision, respectively. The values of the water content at saturation, reported in Table 1, are provided by the manufacturers of the lenses. The harmonic mean thickness, $L_{a v}$, of the lenses completely saturated of water, was measured using an electronic thickness gauge (model ET-3, Redher Development Co., Castro Valley, CA), with precision of $\pm 2 \mu \mathrm{m}$. The results and standard deviation (SD) are given in the fourth column of Table 1. The solution of $\mathrm{NaCl}$ was provided from Sigma-Aldrich and distilled/deionized water (DDI) was obtained from a MilliQ⿱一土丷 ${ }^{\mathrm{TM}}$ purification system with a resistivity greater than $18.2 \mathrm{M} \Omega \mathrm{cm}$.

Table 1

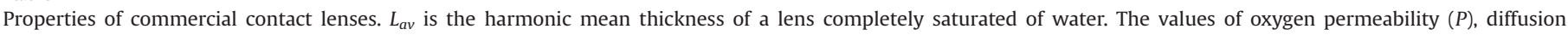
coefficient $(D)$ and solubility $(S)$ have been measured by a potentiostatic method following the procedure described in Section 2.2 .

\begin{tabular}{|c|c|c|c|c|c|c|}
\hline Lens (commercial name) & Material & $\mathrm{H}_{2} \mathrm{O}, w t \%$ & $L_{\mathrm{av}}, \mu \mathrm{m}$ & $D\left(\times 10^{6}\right), \mathrm{cm}^{2} / \mathrm{s}$ & $S\left(\times 10^{5}\right),{ }^{\mathrm{a}}$ & $P$, Barrer $^{\mathrm{b}}$ \\
\hline Seequence & Polymacon & $38.6 \pm 1$ & $95.2 \pm 2.1$ & $0.5 \pm 0.1$ & $18.0 \pm 4.6$ & $8.8 \pm 0.5$ \\
\hline Proclear & Omafilcon A & $62 \pm 1$ & $93.2 \pm 2.2$ & $1.1 \pm 0.2$ & $12.5 \pm 0.2$ & $13.8 \pm 0.4$ \\
\hline Acuvue & Etafilcon A & $58 \pm 1$ & $102.4 \pm 2.2$ & $0.86 \pm 0.1$ & $25.9 \pm 3.7$ & $22.3 \pm 0.6$ \\
\hline Newvues & Vifilcon A & $55 \pm 1$ & $110.3 \pm 2.2$ & $0.83 \pm 0.2$ & $22.7 \pm 6.3$ & $18.8 \pm 0.7$ \\
\hline PureVision $^{\mathbb{B}}$ & Balafilcon A & $36 \pm 1$ & $84.3 \pm 2.1$ & $15.2 \pm 0.5$ & $6.6 \pm 0.4$ & $100.5 \pm 2.4$ \\
\hline Biofinity & Confilcon A & $48 \pm 1$ & $99.2 \pm 2.4$ & $17.8 \pm 0.7$ & $7.8 \pm 0.6$ & $138.6 \pm 4.5$ \\
\hline Acuvue Oasys & Senofilcon A & $38 \pm 1$ & $90.4 \pm 2.3$ & $13.5 \pm 0.5$ & $7.6 \pm 0.5$ & $102.6 \pm 2.5$ \\
\hline Avaira & Enfilcon A & $46 \pm 1$ & $95.2 \pm 2.3$ & $10.1 \pm 0.5$ & $5.4 \pm 0.5$ & $54.5 \pm 2.0$ \\
\hline
\end{tabular}

a Units of solubility are $\mathrm{cm}^{3}$ of gas $/ \mathrm{cm}^{3}$ of polymer/mmHg.

b 1 Barrer: $10^{-11}\left(\mathrm{~cm}^{2} / \mathrm{s}\right)\left(\mathrm{cm}^{3}\right.$ of gas $(\mathrm{STP}) / \mathrm{cm}^{3}$ of polymer $\left./ \mathrm{mmHg}\right)$. 


\subsection{Oxygen diffusion and permeability measurements}

The diffusion characteristics of the lenses were determined utilizing a permeometer model 201T (Rheder Development Co.) commonly used to measure the oxygen permeability through CL.

In the permeometer, the oxygen permeates from one side of the wet hydrogel where the partial pressure of the gas is kept constant $\left(p=p_{L}=155 \mathrm{mmHg}\right.$ ) to the other side facing the cathode of the polarographic cell where the partial pressure is $p_{0} \sim 0$.

In steady state conditions $(t \rightarrow \infty)$, the current intensity can be written as

$I_{\infty}=\frac{n F A D c_{0}}{t_{a v}}$

By assuming that Henry's law holds, $c_{0}=k p$ where $p$ is the pressure of gas at the surface of the hydrogel facing the high pressure side in the experimental device, then Eq. (1) becomes

$I_{\infty}=\frac{n F A P p_{\mathrm{L}}}{t_{a v}}$

where $n$ represent the number of electrons exchanged in the cathodic reaction $(n=4), F$ is Faraday's constant and $A$ the area of the cathode, $t_{a v}$ the average thickness and $P$ the apparent permeability coefficient.

The apparent oxygen diffusion coefficients can be determined as

$D=\frac{t_{a v}^{2} I_{\infty}}{6\left(I_{\infty} t-Q(t)\right)}$

By measuring $I(t)$ as a function of time the values of both the permeability and diffusion coefficients can be readily determined, respectively, by means of Eqs. (2) and (3).

More details and a sketch of the experimental assembly and measuring procedure are given elsewhere [29-31]. The technical characteristics of the CL measured and the experimental results of apparent permeability and diffusion coefficient are given in Table 1.

\subsection{Ion $\mathrm{Na}^{+}$permeability measurements}

The ionic permeability of Hy and Si-Hy lenses can be determined following the experimental setup shown in Fig. 1. In the experimental cell, a lens was attached to the bottom of the donor chamber (A) filled with a volume of $16 \mathrm{~mL}$ of $0.1 \mathrm{M} \mathrm{NaCl}$ solution. Chamber (A) consists of a tube of $16 \mathrm{~mm}$ inner diameter, which was then placed in a receiving chamber (B) containing $100 \mathrm{ml}$ of distilled/deionised (DDI) water (milli-Q). The aperture communicating both donor and receiving chambers is $8 \mathrm{~mm}$ of diameter. The receiving chamber was on a magnetic and stirring heating plate termostatized at $35^{\circ} \mathrm{C}$ to simulate physiological conditions.

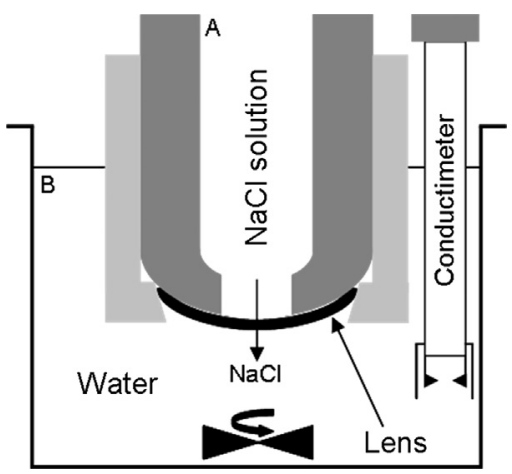

Fig. 1. Illustrative experimental set-up to used to measure the salt permeability.
The conductivity of the solution in the receiving chamber (B) was monitored by a conductivity meter with temperature sensor incorporated (model: Crison CM-35).

Calibration of the conductivity probe was evaluated before each measurement experiment using different $\mathrm{NaCl}$ solutions of known concentration ranging $10^{-1}$ to $10^{-5} \mathrm{M}$. The receptor solution conductivity was monitored using a Crison CM-35 conductivity meter as a function of the time and subsequently converted to $\mathrm{NaCl}$ concentrations using the calibration plot. The salt permeability was calculated as follows [32]:

$\ln \left(1-\frac{2 c_{R}(t)}{c_{L, 0}}\right)=-\frac{2 A P}{V_{R} L}\left(t-t_{0}\right)$

in which $c_{R}(t)$ is the concentration of sodium ions at time $t$ in the receiving chamber, $c_{L, 0}$ is the initial concentration of sodium ions in donor chamber, $A$ is the area of the lens exposed to the salt flux, $L$ represent the average lens thickness in the area exposed, $V_{R}$ is the volume of the receiving cell compartment and $P$ is the apparent permeability coefficient of the sodium ion $\left(P=D k_{m}\right.$, where $k_{m}$ is the lens partition coefficient). If we take into account that the difference in concentration between both sides of the lens, $\Delta c=c_{R}-c_{L, 0}$, is practically constant due to the fact that $c_{R} \gg c_{L, 0}$, then

$c_{R}=\frac{A P c_{L, 0}}{V_{R} L}\left(t-t_{0}\right)$

Thus, plotting the concentration of $\mathrm{Na}^{+}$ions in chamber $\mathrm{B}$ vs. time allows us to obtain the apparent $\mathrm{Na}^{+}$permeability of the lens from the slope of Eq. (5). When the lens has high solute sorption capacity, there will be a time lag before the pseudo-steady state is reached in the permeation experiment. From the curve of concentration vs. time, the time lag $t_{0}$ can be obtained from the intersection of pseudo-state line with the $x$-axis representing time [33]. The diffusion coefficient can be then estimated as

$D=\frac{L^{2}}{6 t_{0}}$

\section{Results and discussion}

\subsection{Computational details}

Bulk structures of Polymacon (pHEMA-based Hy material) and Balafilcon A (Si-Hy material), with different water uptake rates and diffusing particles for diffusion calculations and without diffusing particles for solubility calculations, were packed into five different cubic boxes, with periodic boundary conditions (PBC) to provide an initial density of $1.1 \mathrm{~g} / \mathrm{cm}^{3}$ with cubic box size higher than $30 \times 30 \times 30 \AA^{3}$ (Table 2). Materials used were selected to be similar with polymacon Hy material and Balafilcon A Si-Hy material. While polymacon is now a well known material mainly made of pHEMA, the chemical composition of Balafilcon $A$ is much more complex. However, it is known [15] that the monomer mainly responsible for the high oxygen permeability of Balafilcon A includes, among others, vinyl carbamate TRIS derivative tris (trimethylsiloxy)silylpropyl vinylcarbamate (TPVC). The TPVC molecule contains a hydrophobic silicone portion directly linked to a hydrophilic vinyl carbamate group. This latter moiety provides a significant hydrophilic character to the material. The TPVC molecule is soluble in different proportions with other hydrophilic monomers, such as HEMA and NVP (N-vinylpyrrolidinone). In addition, the vinyl carbamate group provides a "polymerization link" for attachment of hydrophilic monomers responsible for the water uptake of hydrogel and the Si-Hy polymers $[12,19]$. The polymerization reaction of TPVC with NVP, using UV initiation 
Table 2

Entities and amounts incorporated in the simulations.

\begin{tabular}{|c|c|c|c|c|c|c|}
\hline \multicolumn{7}{|l|}{ pHEMA cells } \\
\hline Water in the cell (wt\%) & 10 & 20 & 30 & 34 & 37 & 40 \\
\hline Number of pHEMA15 chains & 5 & 5 & 5 & 5 & 5 & 5 \\
\hline Number of $\mathrm{H}_{2} \mathrm{O}$ molecules & 60 & 136 & 232 & 279 & 318 & 362 \\
\hline Density $\left(\mathrm{g} / \mathrm{cm}^{3}\right)$ & 1.20 & 1.19 & 1.17 & 1.17 & 1.16 & 1.16 \\
\hline \multicolumn{7}{|l|}{ Si-Hy cells } \\
\hline Water in the cell (wt\%) & 10 & 20 & 30 & 34 & 37 & 40 \\
\hline Number of P1 chains & 2 & 2 & 2 & 2 & 2 & 2 \\
\hline Number of PVP9 chains & 2 & 2 & 2 & 2 & 2 & 2 \\
\hline Number of $\mathrm{H}_{2} \mathrm{O}$ molecules & 90 & 200 & 350 & 400 & 470 & 525 \\
\hline Density $\left(\mathrm{g} / \mathrm{cm}^{3}\right)$ & 1.07 & 1.07 & 1.06 & 1.05 & 1.05 & 1.04 \\
\hline
\end{tabular}

PHEMA15 = 15 units of 2-hydroxyethyl methacrylate units (HEMA).

$P 1=4$ units of TRIS +16 units of DMA +4 units of HEMA +25 units of PBVC.

PVP9 $=9$ units of vinyl pyrrolidone (VP).

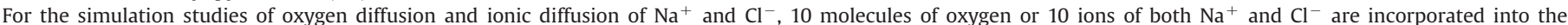
diffusion cell.

The monomer structures are the following.<smiles>C=COC(=O)NCCC[Si](O[SiH3])(O[SiH3])O[SiH3]</smiles>

TPVC<smiles>C=COC(=O)OCCCC[Si](C)(C)O[Si](C)(C)O[Si](C)(C)CCCCOC(=O)OC=C</smiles>

PBVC<smiles>C=CC(=O)N(C)C</smiles>

DMA<smiles>C=C(C)C(=O)OCCO</smiles>

HEMA<smiles>C=CN1CCCC1=O</smiles>

VP methods, results in transparent, high-Dk and relatively lowmodulus water insoluble gels.

All simulations of hydrated hydrogels in the box were accomplished using the discover module of Materials Studio 3.2 [34] molecular modeling package and the pcff91 force field with partial charges defined by force field was used in all calculations [34-38]. This force field has been found also suitable for modeling naked and hydrated protons in polyether systems (PES) with sulfonic acids [39-41]. The system structure energies were minimized with respect to all internal coordinates by a Conjugate Gradient method until the maximum derivative was smaller than $0.1 \mathrm{kcal} /(\AA \AA \mathrm{mol})$, with a limit of 5000 steps; 500 ps of NVT-MD controlled by means of the Andersen thermostat method with a collision ratio of 1.0 and 200 ps of NPT-MD controlled by the Berendsen barostat method with a decay constant of $0.1 \mathrm{ps}$, at $310 \mathrm{~K}$, were performed to obtain relaxed structures with the final system density. In these $\mathrm{MD}$ a $1 \mathrm{fs}$ time step was used and Van der Waals and Coulombic non-bonding interactions were calculated by the Ewald method [42]. Then, the system was subject to a stabilization process consisting on a $200 \mathrm{ps}\left(2 \times 10^{-10} \mathrm{~s}\right)$ long NVT-MD run. The data collecting stage consisted of NVT-MD runs of $5 \mathrm{~ns}$ for all systems. We consider this time large enough to reach a steady state in the study of dissemination of our simulations, and also sufficient to avoid the influence of the initial configurations in the calculation of solubility. Van der Waals and Coulombic nonbonding interactions were calculated by the cell multipole method (CMM) [43-45], the value of the update width parameter was $1.0 \AA$, and the accuracy parameter was set to medium to use third order terms in the Taylor series expansion and explicit interactions from more neighboring cells. The structural results obtained by using the fast CMM methods for the cells agree with the results obtained with the slow Ewald summation method.

Diffusion coefficients $D$ of diffusers in membranes can be calculated by the Einstein diffusion as

$D=\frac{1}{6 N} \lim _{t \rightarrow \infty} \frac{d}{d t} \sum_{i=1}^{N}\left\langle\left[\left[R_{i}(t)\right]-\left[R_{i}(0)\right]\right]^{2}\right\rangle$

The summation at over $N$ the right hand side of the equation is called the mean square displacement (MSD). $N$ is the number of diffusing particles, $t$ is time and $R_{i}(t)$ is the position vector of an ion or molecule $\left(i=\mathrm{O}_{2}, \mathrm{H}_{2} \mathrm{O}, \mathrm{Na}^{+}\right.$, and $\left.\mathrm{Cl}^{-}\right)$at time event $t$. Average MSD curves as a function of time for each diffuser type were calculated. In general, the values of $D$ decrease with increasing time increases, reaching a constant value at long times that reflects steady state conditions $(t \rightarrow \infty)$. When the system reaches this situation the value of the diffusion coefficient is estimated and that indicates that the plot of $\log (\mathrm{MSD}) \mathrm{vs} . \log (t)$ in each case has a slope of $1 \pm 0.03$, [46].

The solubility $S$ of the diffusing gas in a host polymeric matrix could be evaluated as [18]

$S=\frac{1}{k T V} \int \exp \left(-\frac{E(R, \varphi, \theta)}{R T}\right) d V=\frac{1}{k T} \frac{Z}{N}=\frac{Z}{76 N}\left(\frac{\mathrm{cm}^{3}(\mathrm{STP})}{\mathrm{cm}^{3} \mathrm{cmHg}}\right)$

where $k$ is Boltzmann's constant, $V$ is the cell volume, $E$ is the insertion energy and $N$ is the number of random diffuser insertions, employed to compute the partition function $Z$.

The interaction energy between $i$ and $j$ atoms was computed by Van der Waals $(9,6)$ proper of pcff91 force field and the diffuser 
insertion energy, as the sum over all matrix atoms.

$E(i j)=\varepsilon_{i j}\left[2\left(\frac{r_{i j}^{*}}{r_{i j}}\right)^{9}-3\left(\frac{r_{i j}^{*}}{r_{i j}}\right)^{6}\right]$ with $\varepsilon_{i j}=2 \sqrt{\varepsilon_{i} \varepsilon_{j}} \frac{r_{i}^{3} r_{j}^{3}}{r_{i}^{6}+r_{j}^{6}}$ and

$r_{i j}^{*}=\left(\frac{r_{i}^{6}+r_{j}^{6}}{2}\right)^{\frac{1}{6}} \sqrt{a^{2}+b^{2}}$

These solubility calculations have been performed by the method of Widom [19] and modifications of this method proposed by us in the case of rigid polymer matrices [5], well below the glass transition temperature. In the case of a wet hydrogel these approaches are not viable because it seems appropriate to study the process of insertion of molecules considering that the atomic motion is not restricted. In this insertion process it was considered appropriate not to use presets, but to generate a random process of insertion in terms of position and orientation of guest molecules, and study the convergence to constant values of solubility. In this work, $5 \times 10^{6}$ random molecules insertions were performed over 100 conformations obtained by MD simulations and the energy of Eq. (9) was computed as Eq. (9) and is shown in Fig. 2. The insertion of one oxygen molecule could be defined by position vector of oxygen molecule center of mass, $R$, and, the polar coordinates of oxygen atoms respect to center of mass, $\phi, \theta$.

The transport mechanism of diffusers was investigated by computing intermolecular pair correlations functions $g_{A B}(r)$ which represent the probability of finding a pair of particles $A B$ at a distance $r \pm d r$ normalized with respect to the probability

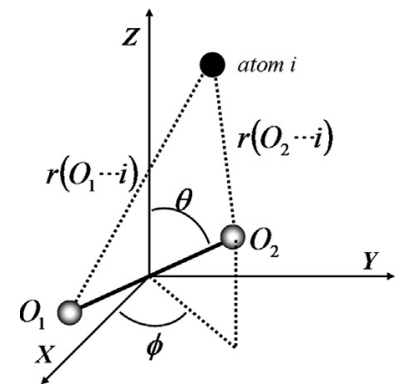

Fig. 2. Position of oxygen molecule in the coordinate system within a given simulation cell. expected for a completely random distribution at the same density. Values of $g_{A B}(r)$ were evaluated as [34]

$g_{A B}(r)=\frac{V}{\left(N_{A} N_{B}-N_{A B}\right)}\left\langle\sum_{i \neq j} \delta\left(\mathbf{r}-\left|\mathbf{r}_{A i}-\mathbf{r}_{B j}\right|\right)\right\rangle$

where $A$ and $B$ represent two kinds of particles (e.g., individual atoms like $\mathrm{Na}^{+}$or $\mathrm{Cl}^{-}$, atomic groups like $\mathrm{H}_{2} \mathrm{O}, \mathrm{O}_{2}$, etc.). The system has a volume $V$ and contains $N_{A}$ particles of kind $A$ and $N_{B}$ particles of kind $B$ with $N_{A B}$ particles belonging simultaneously to both kinds $\left(N_{A}=N_{B}=N_{A B}\right.$ when computing correlation among particles of the same kind; for instance, correlation of the relative positions of ions). Vectors $\mathbf{r}_{A i}$ and $\mathbf{r}_{B j}$ represent the position of particle $i$ of kind $A$ and particle $j$ of kind $B$, so that $\left|\mathbf{r}_{A i}-\mathbf{r}_{B j}\right|$ is the distance between those two particles. The $\delta\left(\mathbf{r}-\left|\mathbf{r}_{A i}-\mathbf{r}_{B j}\right|\right)$ term is set to unity when $\left(\mathbf{r}-\left|\mathbf{r}_{A i}-\mathbf{r}_{B j}\right|\right) \leq d \mathbf{r}$ (i.e., when the difference between desired and actual distance among the two particles is smaller than a tolerance factor $d \mathbf{r}$ and to zero otherwise).

\subsection{Localization of $\mathrm{O}_{2}, \mathrm{Cl}^{-}, \mathrm{Na}^{+}$and $\mathrm{H}_{2} \mathrm{O}$ in soft contact lenses in MDS}

The distribution of the oxygen molecules, $\mathrm{Na}^{+}$and $\mathrm{Cl}^{-}$ions in the polymeric structure of the $\mathrm{Hy}$ and $\mathrm{Si}-\mathrm{Hy}$ materials was investigated by computing intermolecular pair correlations functions $g_{A B}(r)$ using Eq. (10). Figs. 3 and 4 show the pair correlation function between oxygen and water molecules in the Hy (pHEMA) and Si-Hy systems. A close inspection of Fig. 3 shows that the oxygen atoms tend to be located in both areas (two phases), but they present a distance greater than one in the hydrophobic phase (siloxane phase). Therefore, they will be present in both phases but mainly in the hydrophobic one. Then, we hypothesize that in pHEMA systems (Hy), the oxygen molecules will be in both areas but mostly in the hydrophilic one. Fig. 4 plots the pair correlation function (PCF) vs. distance $r(\AA)$ to know if the $\mathrm{Cl}^{-}$and $\mathrm{Na}^{+}$ions ( $A$ type atoms) are closer to type $B\left(\mathrm{SiO}, \mathrm{H}_{2} \mathrm{O}\right)$ or $\left(\right.$ pHEMA, $\left.\mathrm{H}_{2} \mathrm{O}\right)$ for systems with $37 \mathrm{wt} \%$ water. Fig. 4 clearly shows that chlorine ions are in the hydrophilic phase where the first solvatation sphere can be observed around $3 \AA$ and the second solvatation sphere can be more diffusedly seen around the 5-6 A.

Fig. 5 shows the volume of VdW (Van der Waals) corresponding to polymer atoms and diffusing molecules for Hy and Si-Hy of
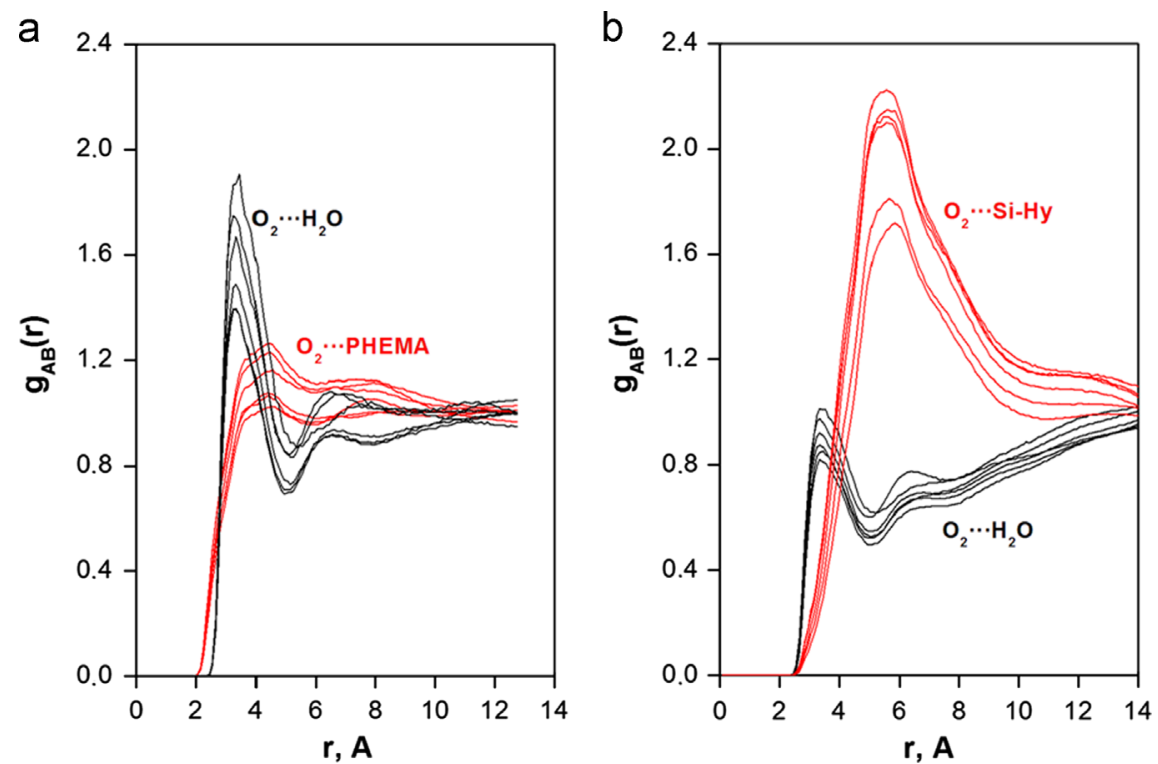

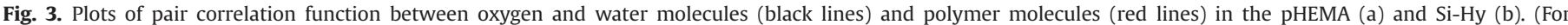
interpretation of the references to color in this figure legend, the reader is referred to the web version of this article.) 
10 and 37 wt\% water content, respectively. From this figure, two types of domains can be observed in Si-Hy matrices. The hydrophilic and hydrophobic phases are separately formed but they coexist and there is a continuous link between them. For example, it can be observed that the aqueous and siloxane phases are separated and that oxygen moves mainly through the hydrophobic phase (siloxane phase) instead of through the hydrophilic phase, suggested to the fact that the hydrophobic phase must offer less
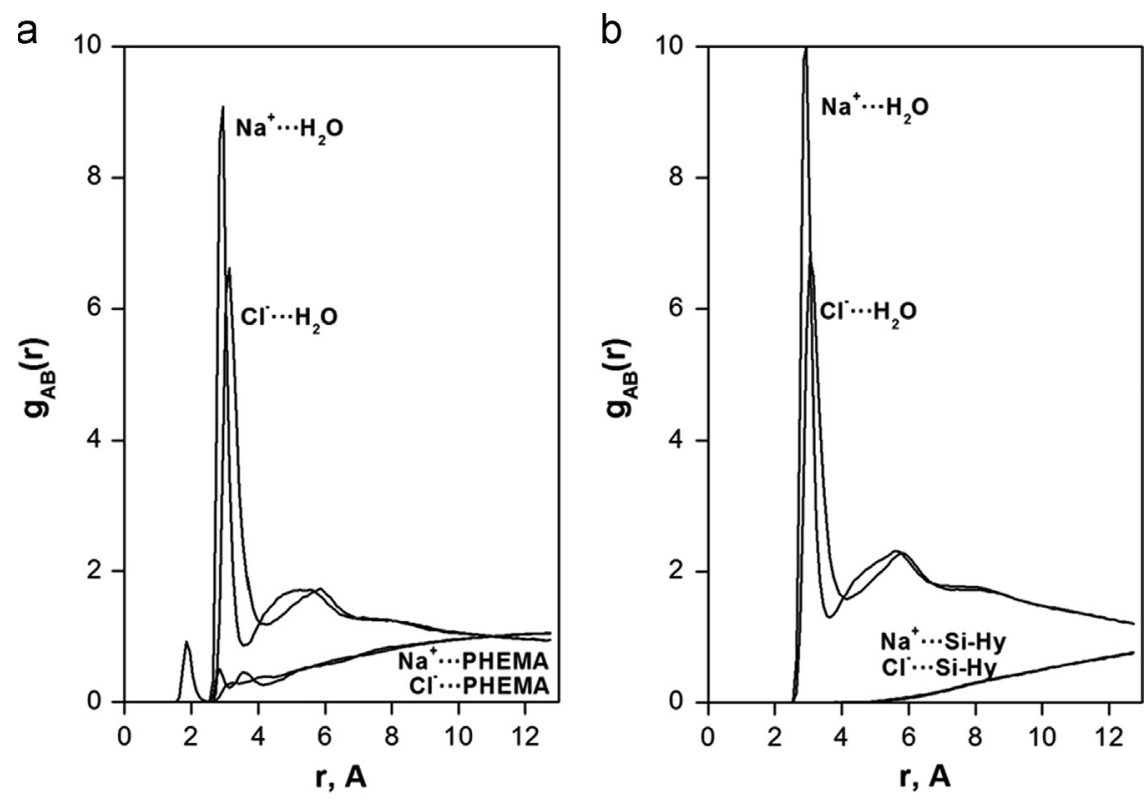

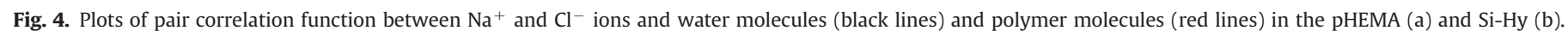
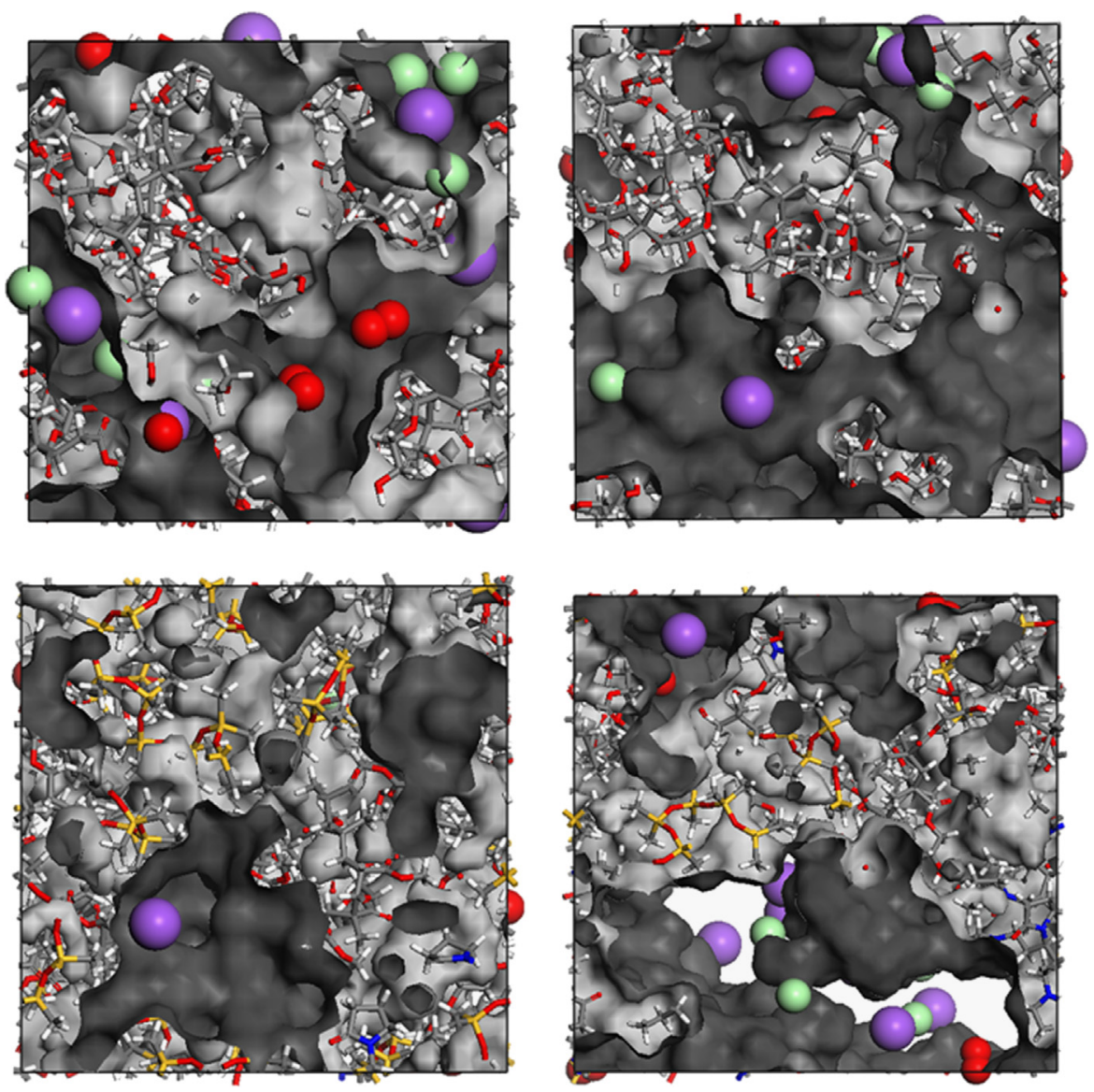

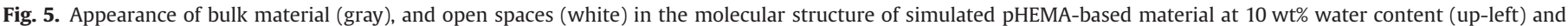

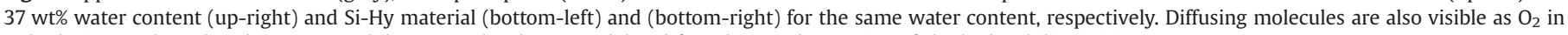
red, $\mathrm{Cl}^{-}$in purple and $\mathrm{Na}^{+}$in green, while $\mathrm{H}_{2} \mathrm{O}$ molecules were deleted for a better observation of the hydrophilic cavities. 

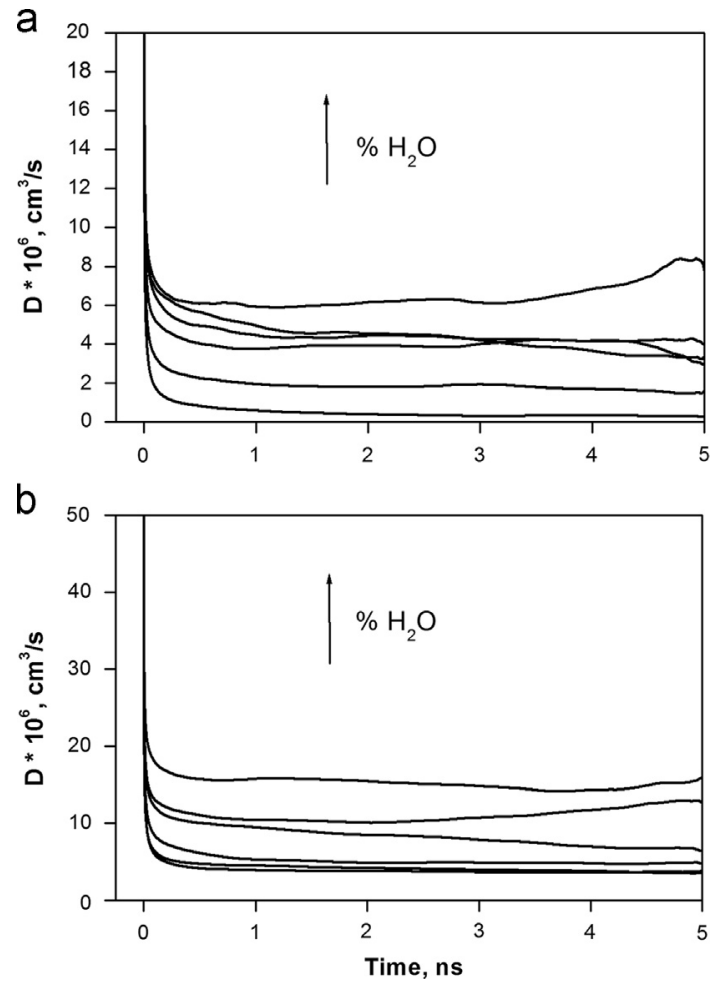

Fig. 6. Plots of diffusion coefficient of oxygen for simulations in (a) pHEMA and (b) Si-Hy contact lens polymers of different water contents (10 and $40 \mathrm{wt} \%$ ) as a function of Molecular Dynamics time.

resistance than the hydrophilic phase due to the small amount of water in its pores being considered that the free volume of those pores will enlarge as the water uptake in the hydrophilic phase increases and the whole polymer swells. Percolation then occurs when the enlarged hydrophilic pores form an interconnected network thus facilitating gas transport. In comparison with Si-Hy, the diffusion of oxygen for Hy materials is carried out homogeneously through of the hydrophilic phase, and its increasing with the water content.

\section{3. $M D S$ and experimental results of $\mathrm{O}_{2}$ permeability}

It is well known that oxygen permeability through Si-Hy is higher than Hy $[15,50,52]$. However, the transport mechanism and how this is achieved are still a matter of debate within the scientific community. In this work we have addressed $\mathrm{O}_{2}$ transport in polymeric materials used in CL production using MDS to obtain the diffusion of oxygen through different material configurations as presented in Table 2. The results of the simulations are compared with experimental results obtained following the procedure described in Section 2.1 and is shown in Table 1. The values of apparent permeability $(P)$ and diffusion $(D)$ coefficients experimentally obtained are given in five and seven columns of Table 1 as average $( \pm S D)$ of five repeated measures. A close inspection of this table shows that our experimental values are closer to the coefficients reported by previous researchers [47-51]. As expected, materials containing siloxane moieties in their structure present oxygen permeability values 5-10 times higher than conventional hydrogel materials. As previously discussed by computing intermolecular pair correlations functions, MDS results agree with this observation showing that $\mathrm{O}_{2}$ molecules diffuse mainly through the hydrophobic parts of the Si-Hy materials while they are distributed in the hydrophilic pats of the Hy materials. Considering that the oxygen permeability of water is much lower than the oxygen permeability through the siloxane pores, it is
Table 3

Values of oxygen diffusion coefficient $(D)$, solubility $(S)$ and permeability $(P)$ obtained from the simulations of conventional (pHEMA-based) hydrogels and $\mathrm{Si}$ Hy materials at different equilibrium water contents (10-40 wt\%).

\begin{tabular}{llllr}
\hline & $\begin{array}{l}\mathrm{H}_{2} \mathrm{O}, \\
\text { wt\% }\end{array}$ & $\begin{array}{l}\mathrm{l} \\
\left(\times 10^{6}\right), \\
\mathrm{cm}^{2} / \mathrm{s}\end{array}$ & $\begin{array}{l}S\left(\times 10^{5}\right), \\
\mathrm{cm}^{3}(\mathrm{STP}) / \mathrm{cm}^{3} \mathrm{mmHg}\end{array}$ & $P$, Barrer \\
\hline pHEMA & 10 & $0.3 \pm 0.1$ & $1.1 \pm 0.2$ & \\
& 20 & $1.7 \pm 0.1$ & $1.0 \pm 0.2$ & $0.3 \pm 0.2$ \\
& 30 & $4.1 \pm 0.1$ & $1.0 \pm 0.1$ & $4.7 \pm 0.4$ \\
& 34 & $4.2 \pm 0.3$ & $1.1 \pm 0.1$ & $4.4 \pm 0.5$ \\
& 37 & $4.5 \pm 0.3$ & $1.1 \pm 0.1$ & $5.0 \pm 0.8$ \\
Si-Hy & 40 & $6.7 \pm 0.7$ & $1.2 \pm 0.2$ & $8.0 \pm 2.2$ \\
& 10 & $3.7 \pm 0.1$ & $7.8 \pm 0.1$ & $28.9 \pm 1.2$ \\
& 20 & $3.8 \pm 0.2$ & $5.6 \pm 0.3$ & $33.6 \pm 2.3$ \\
& 30 & $4.8 \pm 0.1$ & $7.0 \pm 0.5$ & $46.5 \pm 5.2$ \\
& 34 & $7.5 \pm 0.6$ & $6.2 \pm 0.2$ & $73.5 \pm 9.2$ \\
& 37 & $11.3 \pm 0.9$ & $6.5 \pm 0.3$ & $112.5 \pm 7.5$ \\
\hline
\end{tabular}

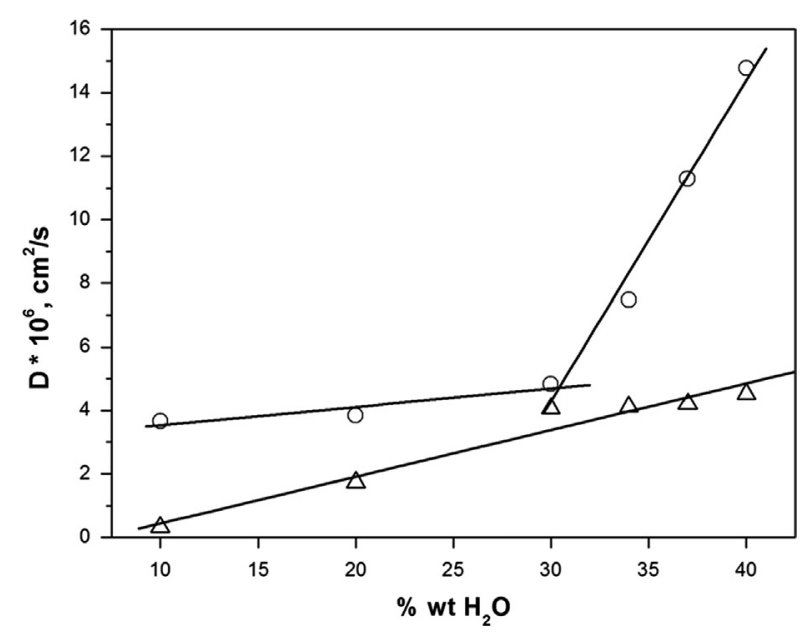

Fig. 7. Oxygen diffusion coefficient in pHEMA-based $\left(-\Delta_{-}^{-}\right)$and $\mathrm{Si}-\mathrm{Hy}\left(-_{-}\right)$membranes as a function of the equilibrium water content of the polymer.

possible to explain the differences in experimental $\mathrm{O}_{2}$ permeability between those two kinds of materials.

As expected the mean square displacement shows increasing values with time. For times large enough, the diffusive regime is reached and $\left\langle[R(t)-R(0)]^{2}\right\rangle$ varies linearly with time, i.e. the slope of the $\log \left\langle[R(t)-R(0)]^{2}\right\rangle \mathrm{Vs} . \log (t)$ plot reaches unity and the diffusion coefficient may be obtained from Eq. (7). Values of the oxygen diffusion coefficient for simulations in $\mathrm{Hy}$ and $\mathrm{Si}$-Hy polymers of different water contents are displayed as a function of time in Fig. 6. All curves show a sharp decrease of the diffusion coefficient with increasing time and the value of this quantity remains nearly constant at both moderate and long times. The average values over the last 4 ns of $D$ and its standard deviation obtained by simulations at temperatures of $37{ }^{\circ} \mathrm{C}(310 \mathrm{~K})$ with different water content are collected in Table 3 . It can be seen that the oxygen diffusion coefficient inside the hydrogels increases with increasing cell water contents.

However, a study of the variation of oxygen diffusion coefficient with water content of the lenses, such as is plotted in Fig. 7 , shows a slope change at a water concentration of $25 \%$ in Si-Hy L . This phenomenon is not observed in conventional pHEMA hydrogels and could be attributed to percolation phenomena. As we can see in Fig. 7, the amount of water content near to $30 \mathrm{wt} \%$ is expected to favours a completely segregation between hydrophilic and hydrophobic phases. In addition, as water concentrates in the 
hydrophilic domain and pushes the volume of the polymer matrix to expand, free volume is created within the hydrophobic domain inducing the formation of pores with very low water content. The percolation of the hydrophobic phase enables the formation of a continuous pathway for the diffusion of oxygen. A close inspection of Fig. 7 shows great difference between the mechanisms of oxygen transport between $\mathrm{Hy}$ and $\mathrm{Si}-\mathrm{Hy}$. It should be noted that the oxygen diffusion coefficient has a nonzero value when the water content is $0 \mathrm{wt} \%$ in Si-Hy materials which is in agreement with previous determination of the oxygen transport through Si-Hy materials in dry conditions [52].

The oxygen solubility was calculated with conformations obtained every $5 \mathrm{ps}$ in MDS so that 100 conformations were selected using the modified particle insertion method. The insertion positions were $5 \times 10^{6}$ times randomly selected in simulation box and the solubility was calculated by Eqs. (8) and (9). Left part of Fig. 8 shows the solubility as a function of particles insertion number in the last conformation obtained by MDS for Hy and SiHy matrices with $37 \mathrm{wt} \%$ of $\mathrm{H}_{2} \mathrm{O}$. Solubility values converged to a constant value after $3 \times 10^{6}$ particle insertions. Right part of Fig. 8 shows the solubility after the $5 \times 10^{6}$ insertions for all conformations obtained by MDS. High fluctuations of solubility values were observed in the first conformations possibly due to shorter time being insufficient to achieve stabilization in MDS, but eliminating the initial period leads to a stable value. The solubility was calculated as the average over the last 50 conformation obtained by MDS.

Table 3 shows the values obtained with our simulations for oxygen diffusion, solubility and permeability coefficients Hy and SiHy CL. A close inspection of Tables 1 and 3, shows a very good correlation between the values of oxygen diffusion obtained experimentally and MDS for lenses of similar water uptake.

Our experimental and MDS results are quite similar to those reported by other researchers [51]. In this sense, Chhabra et al. [51] have found experimentally that diffusion coefficients of oxygen in Polymacon (pHEMA) and Balafilcon $A$ of are $6 \times 10^{-6} \mathrm{~cm}^{2} / \mathrm{s}$ and $15 \times 10^{-6} \mathrm{~cm}^{2} / \mathrm{s}$, respectively. Then, taking into account that the values of oxygen permeability for these lenses are respectively, around 8.4 and 99 Barrers, respectively, then the average values of apparent solubility of these materials must be $1.4 \times 10^{-5} \mathrm{~cm}^{3}\left(\mathrm{O}_{2}\right) /$ $\mathrm{cm}^{3}$ of polymer/mmHg and $6.6 \times 10^{-5} \mathrm{~cm}^{3}\left(\mathrm{O}_{2}\right) / \mathrm{cm}^{3}$ of polymer/ mmHg, for pHEMA and Balafilcon A, respectively. The comparison between the solubility, diffusion and oxygen permeability coefficient obtained experimentally and MDS show good agreement either for Hy and Si-Hy materials.

\subsection{Transport of $\mathrm{Cl}^{-}, \mathrm{Na}^{+}$ions and $\mathrm{H}_{2} \mathrm{O}$}

The knowledge of transport of molecules absorbed in contact lenses as ionic molecules and water, provide a better understanding of whether a contact lens is physiologically compatible with the ocular surface. Though ionic diffusion in polymeric membranes is not a well understood phenomenon, this process presumably involves dissociation of the ions from the salt, subsequent transfer of the anion and cation to the aqueous medium, and finally, diffusion of the ions in the confined water within the polymer matrix. Therefore, ionic mobility will depend on water flux which is a critical parameter together with the water uptake by the lens. It is worth noting that both evaporation present during $\mathrm{CL}$ wear and electro-osmotic drag processes have the potential to severely diminish the CL hydration, causing a significant increase of the ionic resistance. With this hypothesis, the diffusion coefficient of naked ions: $\mathrm{Na}^{+}, \mathrm{Cl}^{-}$and $\mathrm{H}_{2} \mathrm{O}$ absorbed were also evaluated by MDS.

In Fig. 9, we report the variation of the diffusion coefficient of $\mathrm{H}_{2} \mathrm{O}$ and $\mathrm{Na}^{+}$and $\mathrm{Cl}^{-}$ions for pHEMA and Si-Hy materials obtained from MDS. As can be seen in Fig. 9(a), the variation of the diffusion coefficient of water, $\mathrm{Na}^{+}$and $\mathrm{Cl}^{-}$increase with water content. However for Si-Hy lenses, Fig. 9(b), the percolation phenomena occurs in all cases around $30 \mathrm{wt} \%$ water content, in which interconnected segregated phases co-exist. On the other hand, the variation of the diffusion coefficient of $\mathrm{Na}^{+}$and $\mathrm{Cl}^{-}$is linked to water flow through the material. When the diffusion of water is high, the diffusion of ions will also be high and therefore, a better physiological behavior of the lens should be expected because ion diffusion has been shown to be critical for the metabolism of the cornea but also to warrant the movement of the lens on the eye avoiding adherence [48] and improve the comfort [53].

With the aim to compare the results obtained by simulation we also are determined experimentally the sodium permeability
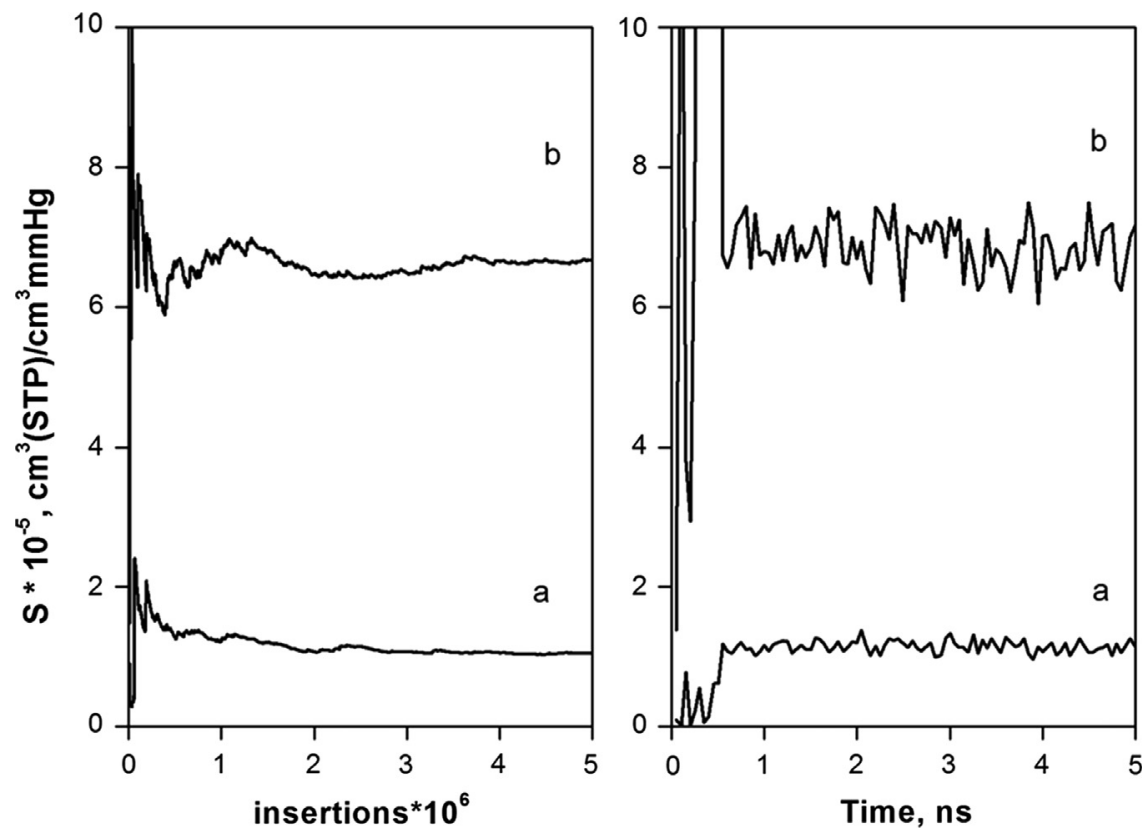

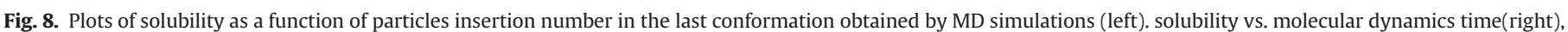
for pHEMA (a) and Si-Hy (b) systems. 

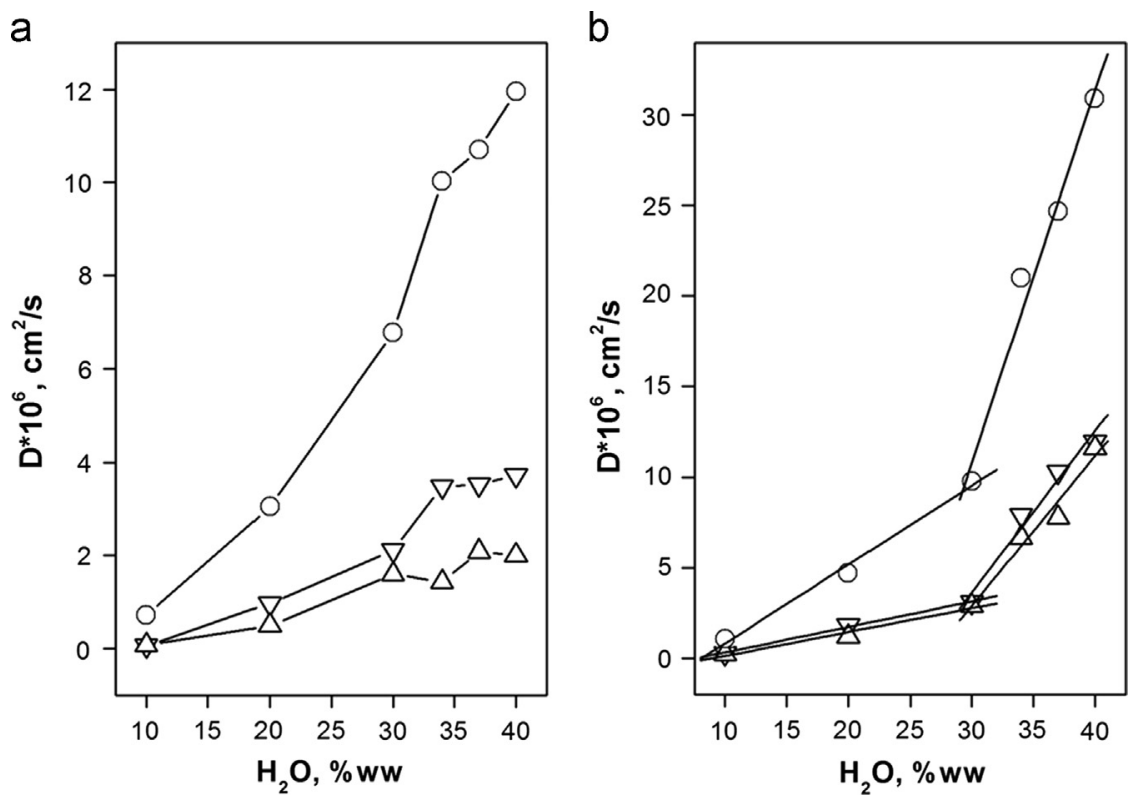

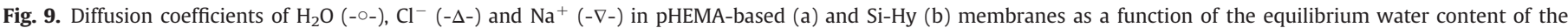
polymer.

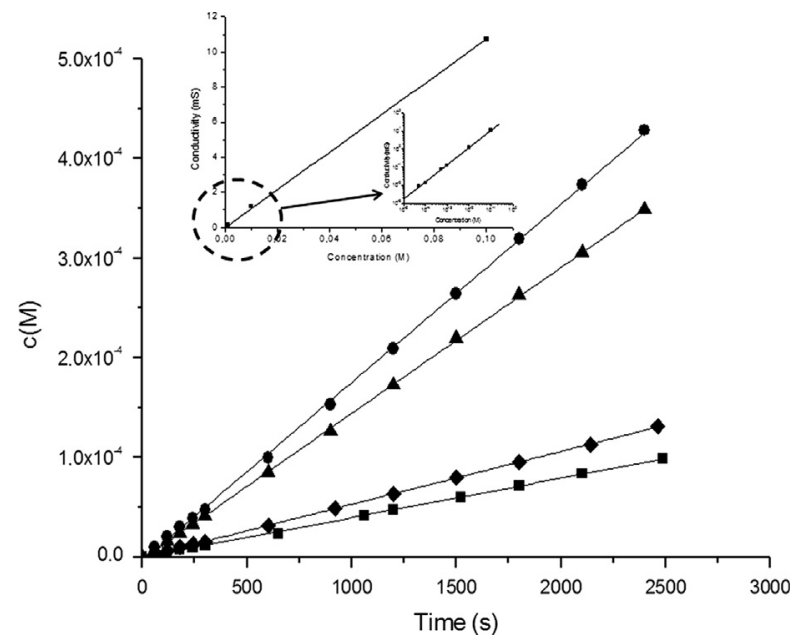

Fig. 10. Salt concentration in the receiving chamber as a function of time for Biofinity (•), PureVision (•), Acuvue2 $(\bullet)$ and Proclear $(\bullet)$ lenses at $35^{\circ} \mathrm{C}$. In the permeation cell, donor volume and concentration is $16 \mathrm{~mL}$ and $0.1 \mathrm{M} \mathrm{NaCl}$, respectively. The aperture communicating donor and receiving chambers is $8 \mathrm{~mm}$ of diameter, corresponding a sample area of $0.50 \mathrm{~cm}^{2}$. In the inset we show the calibration curve correlating conductivity with salt concentration of $\mathrm{NaCl}(\mathrm{ac})$. The line represent adjust to experimental date (in all the cases the correlation coefficient is $r^{2}=0.9998$ ).

using the experimental procedure described in Section 2.2 [54]. The experimental values of permeability and diffusion coefficient of $\mathrm{NaCl}$ are obtained from Eqs. (5) and (6) following the experimental procedure described in Section 2.2. In Fig. 10 we plot the salt concentration of two conventional hydrogel and two Si-Hy lenses (Proclear, Acuvue, PureVision ${ }^{\mathbb{R}}$ and Biofinty) in the receptor chamber as a function of time. Previously to the characterization of the salt transport across the samples, a calibration curve correlating salt concentrations and conductivity has been measured and it is shown in the inset of Fig. $10\left(r^{2}=0.9997\right)$. A value of $0.65 \mu \mathrm{S}$ corresponding to the background conductivity of our Milli$\mathrm{Q}$ water was subtracted from all the conductivity values obtained.

In Table 4 we show the results of permeability and diffusion coefficient of the $\mathrm{Na}^{+}$ions for all the lenses studied. From this values the salt partition coefficient, given by $k_{m}=P / D$, have also
Table 4

Values of apparent salt permeability $(P)$, salt diffusion $(D)$ and partition coefficient $\left(k_{m}=P / D\right)$ for the hydrogel and Si-Hy lenses obtained following the technique described in Section 2.2. The errors of the apparent permeability and diffusion coefficients have been calculated from the parameters of the straight line that fits the experimental values taking into account that each measurement was repeated three times.

\begin{tabular}{lccl}
\hline Lens (commercial name) & $P\left(\times 10^{7}\right), \mathrm{cm}^{2} / \mathrm{s}$ & $D\left(\times 10^{7}\right), \mathrm{cm}^{2} / \mathrm{s}$ & $k_{m}$, au \\
\hline Seequence & $18.4 \pm 1.2$ & $54 \pm 11$ & $0.34 \pm 0.09$ \\
Proclear & $32.8 \pm 1.3$ & $60 \pm 12$ & $0.55 \pm 0.13$ \\
Acuvue2 & $28.9 \pm 1.2$ & $55 \pm 10$ & $0.53 \pm 0.12$ \\
Newvues & $34.1 \pm 1.3$ & $58 \pm 11$ & $0.59 \pm 0.13$ \\
PureVision ${ }^{\mathbb{B}}$ & $6.7 \pm 0.2$ & $18 \pm 3$ & $0.37 \pm 0.07$ \\
Biofinity & $10.5 \pm 0.3$ & $14 \pm 2$ & $0.75 \pm 0.13$ \\
Acuvue Oasys & $0.97 \pm 0.1$ & $2.3 \pm 0.8$ & $0.42 \pm 0.19$ \\
Avaira & $6.0 \pm 0.2$ & $7.2 \pm 1.5$ & $0.83 \pm 0.20$ \\
\hline
\end{tabular}

been also determined and their values are given in the fourth column of this table. A close inspection of Table 4 allows us to observe that the apparent $\mathrm{Na}^{+}$permeability obtained for $\mathrm{Si}-\mathrm{Hy}$ lenses is about 3-4 times lower than that of Hy lenses, and the salt diffusion coefficient increases significantly with increasing water uptake. This should be expected considering that both $\mathrm{D}$ and $k_{m}$ increase with increasing water uptake. For example for $36 \mathrm{wt} \%$ water content Si-Hy material ( lens PureVision), $\mathrm{Na}^{+}$permeability, diffusion and salt partition coefficients are $6.7 \times 10^{-7} \mathrm{~cm}^{2} / \mathrm{s}$, $1.8 \times 10^{-6} \mathrm{~cm}^{2} / \mathrm{s}$ and 0.42 , respectively. On the other hand, Hy materials (Seequence lens corresponding to Polymacon material) with $38.6 \mathrm{wt} \%$ water content show $\mathrm{Na}^{+}$permeability, diffusion and salt partition coefficients of $18.4 \times 10^{-7} \mathrm{~cm}^{2} / \mathrm{s}, 5.4 \times 10^{-6} \mathrm{~cm}^{2} /$ $\mathrm{s}$ and 0.34 , respectively. These results are in agreement with the results obtained by Cerretani et al. [55] where Si-Hy materials have an apparent $\mathrm{NaCl}$ permeability lower than HEMA-based materials, (see Fig. 1 in Reference [55]).

The values of water diffusion coefficient found in our work by MDS are higher in the case of Si-Hy materials, four or five times compared to the experimental values, and lower for conventional hydrogels, such as we can see in Fig. 9, where the values of $\mathrm{Na}^{+}$ diffusion coefficient in Polymacon and Balafilcon A materials are included. A possible explanation for this is that the simulations never represent the actual system configuration, because the experimental 
measurements are performed in aqueous medium where the boundary layer effect is often of great importance, however this effect is not considered in the configuration cell analyzed by the simulation process. Furthermore, simulations cannot mimic the entire composition of the lenses as this information is not completely known. Partition coefficient cannot be obtained by MDS, so it is not possible to compare them with the values experimentally obtained.

\section{Conclusions}

Oxygen transport in Hy and Si-Hy was evaluated by MDS using a modified insertion particle method in two different kinds of materials: Hy and Si-Hy. The structural difference between the two systems, make them ideal candidates to understand the different characteristics observed on the oxygen and ionic transport in CL. In $\mathrm{Si}-\mathrm{Hy}$ materials the aqueous and siloxane phases are separated suggesting a co-continuous structure, and oxygen moves predominantly through the hydrophobic pores (siloxane domain).

The oxygen permeability in Si-Hy materials used as CL is about one order of magnitude larger than that found for Hy materials. The value of the oxygen diffusion coefficient obtained by simulations is roughly similar to that experimentally found using potentiostatic techniques. The oxygen solubility coefficient is about six times higher for Si-Hy materials compared to Hy. The coordination number between the fixed groups (-SiO-) and water in HEMA and the particles $\left(\mathrm{O}_{2}, \mathrm{Cl}^{-}\right.$and $\left.\mathrm{Na}^{+}\right)$is slightly larger than unity.

We observed a percolation phenomenon in the diffusion of oxygen, $\mathrm{H}_{2} \mathrm{O}, \mathrm{Na}^{+}$and $\mathrm{Cl}^{-}$when the water content of the Si-Hy lenses is about $30 \mathrm{wt} \%$. This suggests that the compositions integrating $\mathrm{Si}-\mathrm{Hy} \mathrm{CL}$, increase both oxygen and water diffusion coefficients when the water content increases over 25-30 wt\%.

\section{Acknowledgments}

This work was supported by the project MAT2010-17091 from the Spanish Ministry of Science and Innovation.

\section{References}

[1] O. Wichterle, D. Lim, Hydrophilic gels for biological use, Nature 185 (1960) $117-118$.

[2] B.D. Ratner, Biomedical applications of synthetic polymers, in: F.R.S. Geoffrey Allen, J.C. Bevington, S.L. Aggarwal (Eds.), Comprehensive Polymer Science, vol. 7, 1989, Pergamon Press, Oxford, 1989, p. 201.

[3] N.A. Peppas, H.J. Moyniham, in: NA. Peppas (Ed.), Hydrogels in Medicine and Pharmacy, vol. 2, 1987, CRC Press, Boca Raton, FL, 1987.

[4] K.S. Kazanskii, S.A. Dubrovski, Chemistry and physics of agricultural hydrogels, Adv. Polym. Sci. 104 (1992) 97-133.

[5] T. Tsuruta, Contemporary topics in polymeric materials for biomedical applications, Adv. Polym. Sci. 126 (1996) 1-52.

[6] N.A Peppas, C.T. Reinhart, Solute diffusion in swollen membranes. Part I. A new theory, J. Membr. Sci. 15 (1983) 275-283.

[7] S.P. Nunes, M.L. Sforça, K-V. Peinemann, Dense hydrophilic composite membranes for ultrafiltration, J. Membr. Sci. 106 (1995) 49-56.

[8] S.L. Willis, J.L. Court, R.P. Redman, J.H. Wang, S.W. Leppard, V.J. O'Byrne S.A. Small, A.L. Lewis, S.A. Jones, P.W. Stratford, A novel phosphorycholinecoated contact lens for extended wear use, Biomaterials 22 (2001) 3261-3272.

[9] J. Kim, Q. Conway, A. Chauhan, Extended delivery of ophthalmic drugs by silicone hydrogel contact lenses, Biomaterials 29 (2008) 2259-2269.

[10] P. Erickson, T.L. Comstock, S.G. Zantos, Effects of hydrogel lens transmissibility profiles on local corneal swelling during eye closure, Optom. Vis. Sci. 73 (1996) 169-177.

[11] P. Nicholson, R.C. Baron, P. Chabrecek, J. Court, A. Domscheke, H.J. Griesser Extended wear ophthalmic lens. US Patent no. 5760100, 1998.

[12] G.L. Grobe, J.F. Künzler, D. Seelye, J.C. Salamone, Silicone hydrogels for contact lens applications, Polym. Mater. Sci. Eng. 80 (1999) 108-109.

[13] J.F. Künzler, Silicone hydrogels for contact lens applications, TRIP 4 (1996) $52-59$.
[14] N.G. Gaylord, Oxygen-permeable contact lens composition, methods and article of manufacture. U.S. Patent no. 3808178, 1974.

[15] A. López-Alemany, V. Compañ, M.F. Refojo, Porous structure of Pure vision versus focus night and day and conventional hydrogel contact lenses, . Biomed. Mater. Res. B Appl. Biomater. 63 (2002) 319-325.

[16] H. Eslami, F. Müller-Plathe, Water permeability of poly(ethylene terephthalate): a grand canonical ensemble molecular dynamics simulation study, J. Chem. Phys. 131 (2009) 234904.

[17] H. Eslami, F. Müller-Plathe, Water permeability of poly(ethylene terephthalate): a grand canonical ensemble molecular dynamics simulation study, Macromolecules 40 (2007) 6413-6421.

[18] A.A. Gusev, F. Müller-Plathe, W.F. van Gunsteren, U.W. Suter, Dynamics of small molecules in bulk polymers, Adv. Polym. Sci. 116 (1994) 207-214.

[19] B. Widom, Some topics in the theory of fluids, J. Chem. Phys. 39 (1963) 2808-2812.

[20] X.Y. Wang, A.J. Hill, B.D. Freeman, I.C. Sanchez, Structural sorption and transport characteristics of an ultrapermeable polymer, J. Membr. Sci. 314 (2008) 15-23.

[21] K.L Tung, K.T. Lu, Effect of tacticity of PMMA on gas transport through membranes: MD and MC simulation studies, J. Membr. Sci. 272 (2006) 37-49.

[22] E. Tocci, A. Gugliuzza, L. De Lorenzo, M. Macchione, G. De Luca, E. Drioli, Transport properties of a co-poly(amide-12-b-ethylene oxide) membrane: A comparative study between experimental and molecular modeling results, J. Membr. Sci. 323 (2008) 316-327.

[23] E. Saiz, M.M. López-González, E. Riande, J. Guzmán, V. Compañ, Simulations of diffusive and sorption processes of gases in polyimide membranes: comparison with experiments, Phys. Chem. Chem. Phys. 5 (2003) 2862-2868.

[24] P. Tiemblo, E. Saiz, J. Guzmán, E. Riande, Comparison of simulated and experimental transport of gases in commercial poly(vinylchloride), Macromolecules 35 (2002) 4167-4174.

[25] J. Pozuelo, M.M. López-González, M. Tlenkopatchev, E. Saiz, E. Riande, Simulations of gas transport in membranes based on polynorbornenes functionalized with substituted imide side groups, J. Membr. Sci. 310 (2008) 474-483.

[26] J. Pozuelo, E. Riande, E. Saiz, V. Compañ, Molecular dynamics simulations of proton conduction in sulfonated poly(phenyl sulfone)s, Macromolecules 39 (2006) 8862-8866.

[27] L. Garrido, J. Pozuelo, M. López-González, J. Fang, E. Riande, Simulation and experimental studies on proton diffusion in polyelectrolytes base on sulfonated naphthalenic copolyimides, Macromolecules 42 (2009) 6572-6580.

[28] A. Domschke, D. Lohmann, L. Winterton, On-eye mobility of croft oxygen permeable contact lenses. In: Proceedings of ACS Spring National Meeting, PMSE, San Francisco, 1987.

[29] V. Compañ, J. Garrido, J.A. Manzanares, True and apparent oxygen permeabilities of contact lenses, Optom. Vis. Sci. 69 (1992) 685-690.

[30] V. Compañ, A. Andrio, A. López-Alemany, E. Riande, New method to determine the true transmissibilities and permeabilities of oxygen in hidrogel membranes, Polymer 40 (1999) 1153-1158.

[31] V. Compañ, P. Tiemblo, F. García, J.M. García, J. Guzmán, E. Riande., A potentiostatic study of oxygen tranport through poly(2-ethoxyethyl methacrylate-co-2,3-dihydroxypropylmethacrylate) hidrogel membranes, Biomaterials 26 (2005) 3783-3791.

[32] H. Yasuda, C.E. Lamaze, L.D. Ikenberry, Permeability of solutes through hydrated polymer membranes Part I. Diffusion of sodium choride, Die Makromol. Chem. 118 (1968) 19-35.

[33] M.L. Cheng, Y.M. Sun, Observation of the solute transport in the permeation through hydrogel membranes by using FTIR-microscopy, J. Membr. Sci. 253 (2005) 191-198.

[34] Materials Studio 3.2, Visualizer, Amorphous Cell and Discover Modules, Aceelrys Inc., San Diego, CA, USA, 2005.

[35] H. Sun, Force field for computation of conformational energies, structures, and vibrational frequencies of aromatic polyesters, J. Comput. Chem. 15 (1994) $752-768$.

[36] H. Sun, Ab initio calculations and force field development for computer simulation of polysilanes, Macromolecules 28 (1995) 701-712.

[37] J.R. Hill, J. Sauer, Molecular mechanics potential for silica and zeolite catalysts based on ab initio calculations. 1. Dense and microporous silica, J. Phys. Chem. 98 (1994) 1238-1244.

[38] J.R. Maple, M.J. Hwang, T.P. Stockfisch, U. Dinur, M. Waldman, C.S. Ewig, A.T. Hagler, Derivation of class II force fields. 1. Methodology and quantum force field for the alkyl functional group and alkane molecules, J. Comput. Chem. 15 (1994) 162-182.

[39] H. Sun, S.J. Mumby, J.R. Maple, A.T. Hagler, An ab initio CFF93 all-atom force field for polycarbonates, J. Am. Chem. Soc. 116 (1994) 2978-2987.

[40] J. Ennari, J. Hamara, F. Sundholm, Vibrational spectra as experimental probes for models of ion conducting polyether systems, Polymer 38 (1997) 3733-3744.

[41] J. Pozuelo, F.J. Fernández-Carretero, E. Riande, E. Saiz, V. Compañ, Comparison between the conductivities of protons measured experimentally with the obtained by molecular dynamics simulations in sulfonated polyphenyl sulfones membranes, J. New Mater. Electrochem. Syst. 11 (2008) 87-94.

[42] P.P. Ewald, Die Berechnung Optischer und Electrostatischer Gitterpoten-tiale, Ann. Phys. 64 (1921) 253-287.

[43] L. Greengard, V. Rokhlin, A fast algorithm for particle simulations, J. Comput. Phys. 73 (1987) 325-348.

[44] K.E. Schmidt, M.A. Lee, Implementing the fast multipole method in three dimension, J. Stat. Phys. 63 (1991) 1223-1235. 
[45] H.Q. Ding, N. Karasawa, W.A. Goddard, Atomic level simulations on a million particles: the cell multipole method for Coulomb and London non-bond interactions, J. Chem. Phys. 97 (1992) 4309-4315.

[46] F. Müller-Plathé, Permeation of polymers. A computational approach, Acta Polym. 45 (1994) 259-293.

[47] B. Weissman, S. Schwartz, N. Gottschalk-Katsev, D. Lee, Oxygen permeability of disposable soft contact lenses, Am. J. Ophthalmol. 110 (1990) 269-273.

[48] S.L. Willis, J.L. Court, R.P. Redman, J.H. Wang, S.W. Leppard, V.J. O'Byrne, S.A. Small, A.L. Lewis, S.A. Jones, P.W. Stratford, A novel phosphorylcholine-coated contact lens for extended wear use, Biomaterials 22 (2001) 3261-3272.

[49] M. Chhabra, J.M. Prausnitz, C.J. Radcke, A polarographic metyhod for measuring oxygen diffusivity and solubility in water-saturated polymer films. Application to hypertransmissible soft contact lenses, Ind. Eng. Chem. Res. 47 (2008) 3540-3550.

[50] J.M Gonzalez-Méijome, V. Compañ, E. Riande, Determination of oxygen permeability in soft contact lenses using a polarographic method: estimation of relevant physiological parameters, Ind. Eng. Chem. Res. 47 (2008) 3619-3629.

[51] M. Chabra, J.M. Prausnitz, C.J. Radke, Diffusion and Monod Kinetics to determine in vivo human corneal oxygen-consumption rate during soft contact-lens wear, J. Biomed. Mater. Res. Part B Appl. Biomater. 90B (2009) 202-209.

[52] V. Compañ, A. Andrio, A. López-Alemany, E. Riande, M.F. Refojo, Oxygen permeability of hydrogel contact lenses with organosilicon moieties, Biomaterials 23 (2002) 2767-2772.

[53] P.C. Nicolson, J.U. Vogt, Soft contact lens polymers. An evolution, Biomaterials 22 (2001) 3273-3283.

[54] J. Kim, A. Conway, A. Chauhan, Extended delivery of ophthalmic drugs by silicone hydrogel contact lenses, Biomaterials 29 (2008) 2259-2269.

[55] C. Cerretani, C.C. Peng, A. Chauhan, C.J. Radke, Aqueous salt transport through soft contact lenses: an osmotic-withdrawal mechanism for prevention of adherence, Contact Lens Anterior Eye 35 (2012) 260-265. 